\title{
AN INTEGRATED MULTI-OBJECTIVES OPTIMIZATION APPROACH ON MODELLING PAVEMENT MAINTENANCE STRATEGIES FOR PAVEMENT SUSTAINABILITY
}

\author{
Ankang $\mathrm{JI}^{1}$, Xiaolong XUE ${ }^{1^{*}}$, Yuna $\mathrm{WANG}^{2}$, Xiaowei $\mathrm{LUO}^{3}$, Minggong ZHANG ${ }^{2}$ \\ ${ }^{1}$ School of Management, Harbin Institute of Technology, Harbin, P. R. China \\ ${ }^{2}$ School of Management, Guangzhou University, Guangzhou, P. R. China \\ ${ }^{3}$ Department of Architecture and Civil Engineering, City University of Hong Kong, Hong Kong, P. R. China
}

Received 1 April 2020; accepted 21 September 2020

\begin{abstract}
Addressing the multi-dimensional challenges to promote pavement sustainability requires the development of an optimization approach by simultaneously taking into account future pavement conditions for pavement maintenance with the capability to search and determine optimal pavement maintenance strategies. Thus, this research presents an integrated approach based on the Markov chain and Particle swarm optimization algorithm which aims to consider the predicted pavement condition and optimize the pavement maintenance strategies during operation when applied in the maintenance management of a road pavement section. A case study is conducted for testing the capability of the proposed integrated approach based on two maintenance perspectives. For case 1, maintenance activities mainly occur in $T M_{20}$, $T M_{31}$, and $T M_{41}$, with the maximum maintenance mileage reaching 88.49 miles, 50.89 miles, and 20.91 miles, respectively. For case 2, the largest annual maintenance cost in the first year is $\$ 15.16$ million with four types of maintenance activities. Thereafter, the maintenance activities are performed at $T M_{10}, T M_{31}$, and $T M_{41}$, respectively. The results obtained, compared with the linear program, show the integrated approach is effective and reliable for determining the maintenance strategy that can be employed to promote pavement sustainability.
\end{abstract}

Keywords: pavement maintenance management, maintenance strategy, pavement sustainability, Markov chain, Particle swarm optimization.

\section{Introduction}

The condition of road pavement is vulnerable to the impact of uncertain environmental factors and traffic loads, resulting in pavement deterioration over time (Chou \& Le, 2011; Elhadidy et al., 2015; Neal \& Pro, 2020; Pantuso et al., 2019). The deteriorating pavement is prone to cause severe structural damage and shorten the service life (U.S. Department of Transportation, Federal Highway Administration, 2020; Biondini \& Frangopol, 2016; Roads $\&$ Bridges, 2020; Kim et al., 2019). Timely and appropriate maintenance is required to ensure pavement safety and extend service life (Barone \& Frangopol, 2014). Considering the limited maintenance budget, costly maintenance activities, and overall high-quality conditions with sustaining and improving economic growth, maintenance strategies are urgently needed.

Optimized maintenance strategies, which have garnered significant attention by researchers, have the ability to produce a time-based pavement maintenance program to promote pavement sustainability. The optimized maintenance strategies could be conducted by the optimization algorithm, which can provide the most appropriate intervention with respect to several constraints (Santos et al., 2019; Yepes et al., 2016). However, the pavement conditions would be subject to substantial uncertainty, which may cause deviations in maintenance strategies to be inconsistent with the conditions that occur on the pavement. Thus, full consideration should be given to the existence of road pavement uncertainty when determining maintenance strategy.

A road deterioration model or road failure model to address the posed challenges has garnered significant attention, such as the random variable deterioration model (Pandey et al., 2009) and spatial variability models (Lea \& Harvey, 2015). Though the literature has shown that

${ }^{\star}$ Corresponding author. E-mail: xlxue@hit.edu.cn 
these models leveraged for predicting future pavement conditions is effective, its applicability to road pavement deterioration has not been fully validated due to the small number of cases. A popular and widely applied approach, the Markov Chain (MC), has been developed to address the uncertainty issue for predicting future pavement conditions. Widely existing methods applied the MC to predict future pavement conditions by the state transition probability matrix (TPM) (Pérez-Acebo et al., 2018; Saha et al., 2017; Tabatabaee \& Ziyadi, 2013). Those include the research conducted by Mandiartha et al. (2017), which applied the MC to model the road pavement deterioration process. Further contributions within the road pavement deterioration can be referred to Gao and Zhang (2013), Lethanh and Adey (2013), Surendrakumar et al. (2013), Noortwijk and Frangopol (2004). These studies indicate that MC is perfectly suitable for application in the uncertain road pavement deterioration process over the life cycle. The MC-based models can be the appropriate representation of the road pavement deterioration process over its entire life-cycle by accounting for the impact of uncertainty (Lethanh et al., 2015). Meanwhile, the MC-based models could be revised to account for proper modeling of the road pavement system when additional information regarding the actual road pavement deterioration is available (Chootinan et al., 2006). However, at the maintenance planning phase, many alternative strategies could be available with prior knowledge of the road pavement conditions. It seems almost impractical to enumerate all scenarios, because there is plenty of scenario combinations.

This research, therefore, presents an integrated approach to determine maintenance strategies for stakeholders to promote pavement sustainability in road maintenance management with $\mathrm{MC}$ and an efficient optimization algorithm considering several constraints, such as limited maintenance budget and overall high-quality conditions. MC, which has the capability to predict the pavement conditions by the state TPM over the life cycle, is used to analyze future pavement conditions. Particle swarm optimization (PSO), a random search algorithm based on group cooperation developed by simulating the foraging behavior of birds (Gopalakrishnan, 2013), is used to search the optimal solutions in plenty of scenario combinations by leveraging its advantages on multi-objective optimization. The integrated approach MC-PSO is designed to be an efficient multi-objective optimization decision-making tool for stakeholders to effectively formulate an optimal maintenance strategy.

The organization of this research is as follows. Section 1 presents a literature review about the maintenance optimization management. Section 2 describes the theoretical background and the main features of the proposed optimization system. The research objective is described in Section 3; the mathematical formulations of two maintenance perspectives aim to maximize the pavement performance and minimize the maintenance cost, respectively. Section 4 proposes the methodology and describes the MC, PSO, MC and PSO integration as well as the MC-PSO solution procedure. Section 5 presents the numerical case study conducted using the proposed integrated approach. The discussions are presented in Section 6. The last section draws conclusions.

\section{Literature review}

Sufficient pavement maintenance activities by the management of the road agency are of crucial importance for promoting pavement sustainability (Santos et al., 2017, 2018; Vyas et al., 2019). In general, the maintenance activities are primarily applied to project-level and network-level pavements (Chootinan et al., 2006), all of which are applicable to the maintenance optimization problem.

Project-level pavement maintenance in this context means detailed maintenance for a project, generally considering the material, environment, and cost. Lamptey et al. (2008) focused on the preventive maintenance schedule optimization by selecting the best combination of preventive maintenance treatments and timings, the presented method applied in a case study demonstrated that it was feasible for developing rational and consistent preventive maintenance schedules in the interval resurfacing events. Yu et al. (2013) integrated life cycle assessment and life cycle cost analysis to optimize the pavement maintenance plans in the pavement maintenance field; the results showed that the developed method was effective in reducing both the energy consumption and greenhouse gas emission for conducting the maintenance plans. Further, Yu et al. (2015) proposed a multi-objective optimization model integrating three elements (pavement performance, cost, and environment) to optimize the asphalt pavement maintenance plans at the project level; the results showed that the model was helpful to optimize the asphalt pavement maintenance plans owing to the quantitatively interactive relationship of the three elements. However, at the project level, the challenge remains to develop a long-term maintenance strategy owing to a project being only part of the road network; consequently, only conducting a project-level maintenance strategy would be prone to the neglect of the integrity of the entire road network, so a maintenance strategy for the road network is typically needed.

The network-level pavement maintenance, which commonly considers pavement maintenance from the perspective of the overall road network, is an important application of the pavement maintenance field. In practice, the network-level pavement maintenance activities are usually constrained by many aspects, such as pursued maintenance targets and limited maintenance budget (Torres-Machi et al., 2017), consequently posing a difficult problem for road managers. Therefore, finding a suitable and reliable approach for assisting managers to develop network-level pavement maintenance strategies is an urgent need. Over the past few years, mathematical methods have garnered significant attention. The studies on fuzzy logic (Moazami et al., 2011; Singh et al., 2018) and linear program (Jesus et al., 2011; Ramachandran et al., 2019) 
provide effective methods for pavement maintenance strategies. The fuzzy logic was proposed by Moazami et al. (2011) to develop a prioritization model integrated with the analytical hierarchy process to prioritize maintenance alternatives; the results demonstrated that the model could enable managers to prioritize maintenance of damaged areas based on their conditions and to achieve the effectiveness of budget al.ocation. Likewise, Singh et al. (2018) presented two approaches of fuzzy mathematical analysis, Fuzzy Analytical Hierarchy Process (FAHP) and Fuzzy Weighted Average (FWA), to conduct strategic planning for maintenance and rehabilitation of pavements. The two approaches were applied to prioritize the pavement stretches; the results indicated that the comparative application of the two approaches could effectively obtain reasonable decisions. Another mathematical method linear program was used in the studies by Jesus et al. (2011) and Ramachandran et al. (2019) to obtain optimal solutions for allocating highway maintenance budget and resources respectively for pavement maintenance. Undeniably, these methods performed well in providing maintenance strategies. However, they could become prohibitively computationally demanding and complex as the problem size or dimension increases.

Recently, optimization program algorithms have been developed for determining maintenance strategies. The optimization program algorithm Genetic algorithm (GA) has been widely applied to address maintenance strategy problems. Morcous and Lounis (2005) and Chootinan et al. (2006) used GA to search optimal maintenance alternatives that consider minimizing the life-cycle cost of an infrastructure network, and the results showed that the proposed method could provide a Pareto-optimal solution of minimizing the life-cycle cost while keeping the network condition above a predefined threshold value. In other works, Bosurgi and Trifirò (2005) conducted research on pavement maintenance management using artificial neural networks and GA, the obtained results highlighted the approach was very effective. Yang et al. (2015) applied GA to build a new pavement management system for optimal pavement maintenance and rehabilitation strategy according to the optimization aims of minimizing maintenance cost and maximizing the pavement condition. The results indicated that the proposed method was a valuable tool to help managers make decisions. Undeniably, the simulation-based GA methods have the capability to accomplish multi-year planning of pavement maintenance activities for a specific situation. However, the need to encode and decode programs in the application process of GA can easily cause barriers that limit the widespread application of GA.

To obtain an appropriate multi-objective optimization method, researchers have made unremitting efforts. The improved non-dominated sorting genetic algorithm (NSGA-II) has been applied to achieve multi-objective optimization analysis (Khavandi Khiavi \& Mohammadi, 2018; Konak et al., 2006). However, the optimization effect of the algorithm is not good when solving high-dimensional and multi-objective problems. In another work, an improved artificial bee colony algorithm was proposed to address the pavement resurfacing optimization problem (Panda \& Swamy, 2018). However, this algorithm is prone to fall into a local optimum and the convergence rate is slow in the later evolution. Furthermore, the applicability of these methods to maintenance strategy needs to be further explored. In various optimization methods, PSO has been widely considered. PSO is an efficient search method to obtain the optimal solution. Tayebi et al. (2014) demonstrated that when conducting the programming of pavement maintenance activities, PSO has the advantages in convergence and accuracy compared with GA. In previous studies, PSO has been successfully applied to address challenges in several fields, such as nondestructive evaluation of the pavement system (Gopalakrishnan, 2010), sustainable engineering design (Chou \& Le, 2014). More importantly, several studies have focused on pavement maintenance management (Ahmed et al., 2019a, 2019b; Chang, 2013; Suresh \& Kumarappan, 2013). These remarkably successful applications of PSO motivate the authors to further examine its performance in determining maintenance strategies. Therefore, we apply the PSO in this research to achieve reliable and practical maintenance strategies.

\section{Multi-objective optimization for maintenance under uncertainty}

\subsection{Multi-objective optimization solution for maintenance}

Multi-objective optimization is commonly used to deal with more than one objective of a real-life problem (Alothaimeen \& Arditi, 2019). Multi-objective optimization is a field of multi-criteria decision-making, which is a mathematical problem involving the simultaneous optimization of multiple objective functions. Multi-objective optimization has been applied in many scientific fields, as well as engineering, economy, and logistics. In general, competition and incompatibility between objectives make finding an optimal solution satisfying all constraints an important task. The optimal solution for the multi-objective problem is also called Pareto-optimal solution (Figueredo et al., 2020).

For multi-objective optimization considering maintenance problems, the objective function can be defined as:

$$
\left\{\begin{array}{cc}
\min f(x)=\left[f_{1}(x), f_{2}(x), \cdots, f_{n}(x)\right]^{T} \\
\text { s. t. } & x \in X \\
& X \subseteq R^{m}
\end{array},\right.
$$

where $f_{1}(x), f_{2}(x), \cdots, f_{n}(x)$ represent $n$ objective functions for the objective of minimizing them; $X$ represents variable feasible region; $X \subseteq R^{m}$ is the constraint set of decision variables. 
In light of the Pareto-optimal solution extended to solution of the multi-objective optimization, a solution $x^{*} \in X$, if $\forall x \in X, f\left(x^{*}\right)<f(x)$, then $x^{*}$ is called the absolute optimal solution of the multi-objective optimization. If not existing $x \in X$, making $f(x)<f\left(x^{*}\right)$, then $x^{*}$ is called the Pareto-optimal solution (Yuan et al., 2017).

\subsection{Optimization-based decision-support system for pavement maintenance management}

The optimization-based road pavement maintenance strategy system consists of the following six modules: (a) data statistics module; (b) prediction module; (c) simulation module; (d) decision-support module; (e) results report module; and (f) data management module. These modules are integrated as shown in Figure 1. The data collection module is used as the initial data input port based on the data survey. The prediction module uses the TPM of the MC to predict future pavement conditions. The simulation module hosts the PSO to be applied based on objectives and constraints to simulate feasible solutions for finding the multi-objective optimization solution and selecting the best optimal solution (i.e. Pareto-optimal solution). In this research, the objectives are from two maintenance perspectives: maximizing the pavement performance and minimizing the maintenance cost, and the Pareto-optimal solution is the best maintenance activities that can be performed with the constraints. A detailed description of the results with the optimal maintenance strategy and pavement's function quality report is finally presented through the results report module. In addition, the existence of a data management module is responsible for implementing data storage, realizing data transfer, and processing between each module.

\section{Research objective}

The research objective is to conduct pavement management to aid pavement stakeholders to develop optimal maintenance strategies utilizing the model for enhancing pavement sustainability and considering not only the limitation of the maintenance requirements incurred by the road agencies, but also satisfying the benefit of stakeholders. To determine whether or not the models are a good fit, the following assumptions are made in the proposed maintenance model: (a) predicted pavement conditions can reflect the actual pavement conditions; (b) the unit maintenance costs for each pavement state in each year discounted to the start time remain the same; (c) the deterioration period of each pavement state remains the same, and the pavement state can only deteriorate to a worse pavement state, not moving to a better pavement state unless maintenance measures are taken; (d) maintenance activities are periodically performed according to maintenance strategies. The suitable model constructed in this research includes the following steps: (a) identification of decision variables; the decision variables are designed to represent all feasible maintenance activities to be performed in each pavement state per year; (b) establishment of the objective function; the objective function is an important part of the optimal approach and is of interest to stakeholders; (c) establishment of constraint set; the constraint set to be considered is to ensure the solution satisfying the requirements of logic, road pavement miles, road pavement quality condition, and budget limit.

Notwithstanding any pavement management practices and requirements of each road agency, the optimization model for achieving objectives (two maintenance perspec-

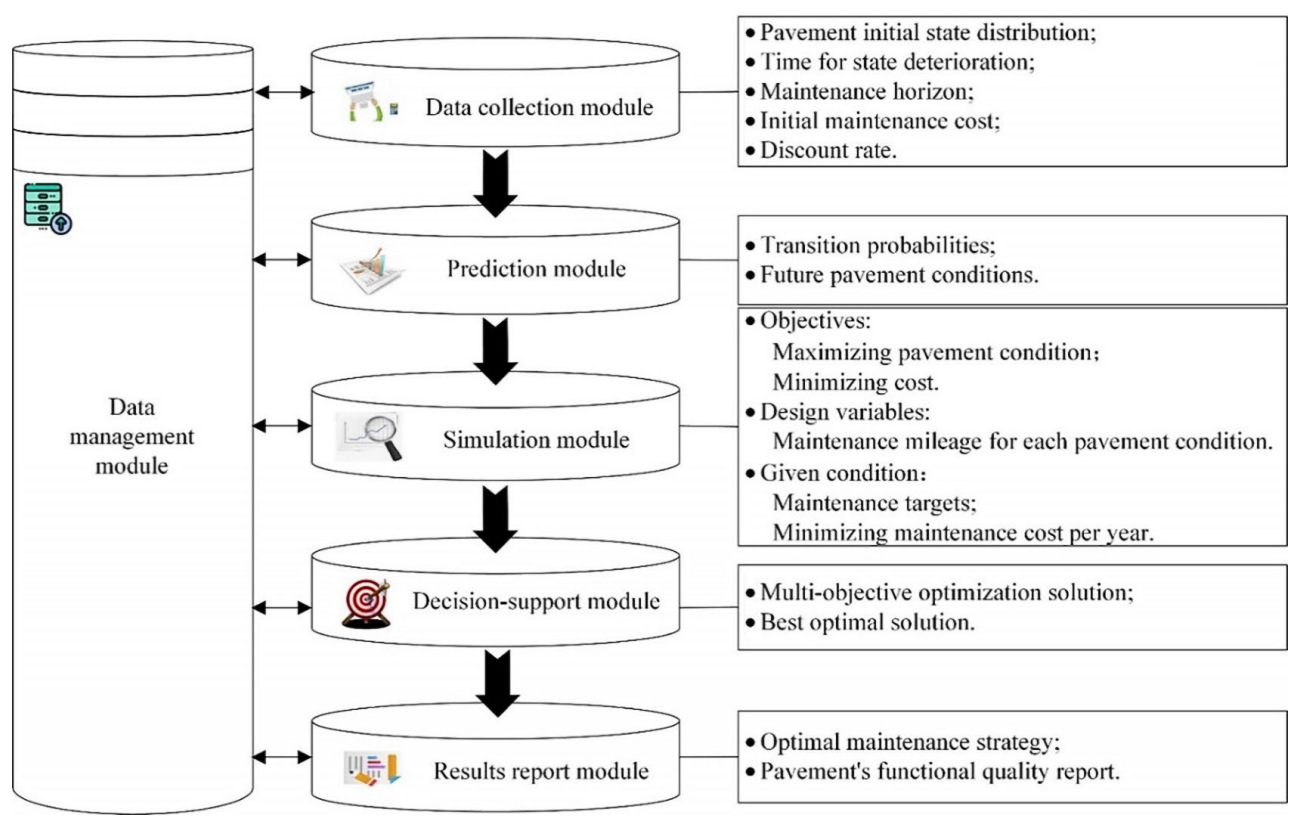

Figure 1. Flowchart of the computational platform for optimum maintenance strategy 
tives) presented in this research can be mathematically expressed as follows:

$$
\begin{aligned}
& \text { Minimize } \sum_{i=0}^{n} \sum_{j=0}^{n} w_{i}^{s} S_{i}^{t}=\operatorname{Minimize}\left(\sum_{i=0}^{n} \sum_{j=0}^{n} w_{i j} T M_{i j}^{t}+R\right) \\
& \text { Minimize } \sum_{i=0}^{n} \sum_{j=0}^{n} C M_{i j}^{t} T M_{i j}^{t} .
\end{aligned}
$$

Subject to:

$$
\begin{aligned}
& S_{i}^{t}=S D_{i}^{t}+T M_{i_{-} \text {plus }}^{t}-T M_{i_{-} \text {minus }}^{t} ; \\
& T M_{i_{-} \text {plus }}^{t}=\sum_{j=0}^{n} T M_{j i}^{t} ; \\
& T M_{i_{-} \text {minus }}^{t}=\sum_{j=0}^{n} T M_{i j}^{t} ; \\
& \sum_{i=0}^{n} T M_{i_{-} \text {minus }}^{t}=\sum_{i=0}^{n} T M_{i_{-} \text {plus }}^{t} ; \\
& S D_{i}^{t}=S^{t-1} \times T M P ; \\
& S D_{i}^{t} \geq T M_{i_{-} \text {minus }}^{t} ; \\
& B_{\text {total }}^{t} \geq C_{\text {total }}^{t}=\sum_{i=0}^{n} \sum_{j=0}^{n}\left(T M_{i j}^{t} \times C_{i j}^{t}\right) ; \\
& C_{i j}^{t}=C_{i j}^{i n i} \times(1+d)^{t} ; \\
& S_{i}^{t}, S D_{i}^{t}, T M_{i_{-} \text {plus }}^{t}, T M_{i_{-} \text {minus }}^{t}, T M_{i j}^{t}, T M_{j i}^{t} \geq 0,
\end{aligned}
$$

where $S_{i}^{t}$ is the road pavement mileage in state $i$ in year $t$, and the initial road pavement mileage in different states is computed based on Combined Condition Index (CCI) values; $w_{i}^{s}$ and $w_{i j}$ represent the weights of pavement in state $i$, which define priorities for each pavement condition when transferring the maintenance mileage from state $i$ to state $j$, respectively; $T$ is the maintenance horizon as required by the road agency; $n$ is the number of pavement state; $T M_{i j}^{t}$, called maintenance activity, is the transferred maintenance mileage from state $i$ to state $j$ in year $t$; $R$ is the constant term; $S D_{i}^{t}$ is the road pavement mileage after deterioration in state $i$ in year $t$, which is determined by the road pavement mileage of different states in the previous year and the transfer probability in TPM; TPM is the transition probability matrix of the Markov chain for predicting the future pavement conditions; $T M_{i_{-} \text {plus }}^{t}$ represents increased mileage to road pavement state $i$ through maintenance in the year $t ; T M_{i_{-} \text {minus }}^{t}$ represents reduced mileage from road state $i$ by maintenance in the year $t$; $B_{\text {total }}^{t}$ is the total maintenance budget incurred by the road agencies for conducting maintenance activities in year $t$; $C_{\text {total }}^{t}$ is the total maintenance cost in year $\mathrm{t}$; $C_{i j}^{t}$ represents the cost per mile of maintaining the road pavement condition from state $i$ to state $j$ in year $t ; C_{i j}^{i n i}$ represents the initial cost per mile of maintaining the road pavement from state $i$ to state $j ; d$ represents the discount rate.

Eqn (2) expresses the minimization of the pavement condition in different states through the priority adjust- ment by weights. To minimize maintenance cost, the objective function is expressed in Eqn (3). Constraints (4) corresponding to the objective equation express the road pavement mileage in state $i$ in year $t$ as a set of functions of the road pavement mileage after deterioration $\left(S D_{i}^{t}\right)$, the increased mileage ( $T M_{i_{-}}^{t}$ plus $)$, and the reduced mileage $\left(T M_{i_{-} \text {minus }}^{t}\right)$. Constraints (5) and (6) corresponding to constraints (3) express the transferred maintenance mileage related to the state $i$. Constraints (7) show the equal relationship between the increased mileage $\left(T M_{i_{-} \text {plus }}^{t}\right)$ and the reduced mileage ( $T M_{i_{-} \text {minus }}^{t}$ ) over all pavement states in year $t$, in other words, the transfer mileage is the increased mileage in the state $i$, and in another state, it is the reduced mileage. Constraints (8) express the road pavement mileage after deterioration $\left(S D_{i}^{t}\right)$ related to the previous year's road pavement mileage $\left(S^{t-1}\right)$ and the transfer probability in TPM. Constraints (9) indicate the limit of the reduced mileage ( $\left.T M_{i \text {-minus }}^{t}\right)$, the maximum of which cannot exceed the road pavement mileage after the deterioration in state $i\left(S D_{i}^{t}\right)$. Constraints (10) represent the budget limit that can be imposed on road pavement maintenance activities. Constraints (11) corresponding to constraints (10) express the time value of unit maintenance cost. Constraints (12) represent logical non-negativity constraints.

\section{Methodology}

\subsection{Markov Chain (MC) approach}

The Markov chain (MC) is a commonly used probabilistic model for pavement performance prediction, which treats pavement condition indicators (e.g., crack index, ride index, and rut index) as random variables and thus can explain the uncertainty associated with pavement deterioration. $\mathrm{MC}$ is a discrete-time stochastic process that involves using transition probabilities to predict future pavement conditions by the state transition over time sequence (Tee et al., 2018). Transition probabilities describe the probabilities that a road pavement section will stay in its existing state or transit to another state at the beginning of the following year. One of the characteristics of the MC is that the probability of a state transition at any given time depends only on its current state. Thus, suppose the state sequence is $S^{0}, S^{1}, \cdots, S^{t}, S^{t+1}, S^{t+2}, \cdots$, the state $S^{t+1}$ of time $t+1$ is only related to state $S^{t}$ of time $t$. The mathematical expression satisfies the equation as follows:

$$
\operatorname{Pr}\left(S^{t+1} \mid S^{0}, S^{1}, \cdots, S^{t}, S^{t-1}, S^{t}\right)=\operatorname{Pr}\left(S^{t+1} \mid S^{t}\right) .
$$

Then $S=\left\{S^{0}, S^{1}, \cdots, S^{t}, S^{t+1}, S^{t+2}, \cdots\right\}$ is MC. The MC can be computed based on the transition probability between any two states. The transition probability of a road pavement section can be expressed as follows:

$p_{i j}=\operatorname{Pr}\left(S^{t+1}=j \mid S^{t}=i\right)$ subject to $\forall i, j \in S S, t \in T$,

where the $p_{i j}$ is the transition probability of a road pavement section from state $i$ at the beginning of year $t$ to state 
$j$ at the beginning of year $t+1$, which satisfies $p_{i j} \geq 0$ and $\sum_{j} p_{i j}=1 . S S$ is the state space; and $T$ is the maintenance

The most important aspect in using transition probabilities for analyzing the future pavement conditions subject to initial pavement conditions is to apply TPM (Osorio-Lird et al., 2018). A TPM represents the set of state transition probabilities of pavement conditions to be experienced, which is uncertain in nature and highly influenced by various factors (Moreira et al., 2018). The TPM can be expressed as:

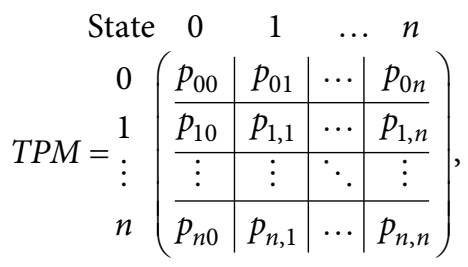

where $n$ is the number of pavement states. To the left and top of the transition probability matrix in Eqn (15) are the pavement states.

Different TPMs can be used for different road pavement conditions. The most common way to determine TPM is based on historical data. On the other hand, an alternative feasible method to determine TPM is based on the rich experience and knowledge of engineering practitioners to estimate the deterioration period of adjacent pavement states, and then compute the transition probability of the pavement condition moving to the state $j$ from the given state $i$. The transition probability of road pavement can be expressed as:

$$
p_{i j}=\left\{\begin{array}{cc}
\prod_{m=i}^{j-1} \frac{1}{t_{m(m+1)}^{D} \cdot\left(1-\frac{1}{t_{j(j+1)}^{D}}\right),} \quad i<j \\
1-\frac{1}{t_{j(j+1)}^{D}}, & i=j
\end{array},\right.
$$

where $t_{m(m+1)}^{D}$ and $t_{j(j+1)}^{D}$ represent the deterioration period of adjacent pavement states.

\subsection{Particle swarm optimization (PSO)}

PSO is a population-based optimization tool for solving various complex problems (Eberhart \& Kennedy, 1995; Feng et al., 2018). For the problem of the present research, the PSO is applied to search the optimal strategy to maintain the road pavement for sustainable service under various constraints. Each particle of the PSO represents a feasible maintenance activity. PSO simulates the movement of those particles to search the optimal position in search space. The particles have velocities that can be dynamically adjusted according to their own flight experience and the flight experience of their companions to change their position in the search space and memory of its previous best position as personal best (pbest) in the search space. The PSO can keep the best value and position in particles of the swarm during the simulate process, which is called as gbest. Each particle moves toward its best previous position and toward the best particle in the whole swarm.

Suppose that in search space, the velocity and position of the $i$-th particle for the next iteration $k+1$ can be expressed as follows:

$$
\begin{aligned}
& v_{i}(k+1)=w(k+1) \times v_{i}(k)+c_{1} \times r_{1} \times\left(\text { pbestx }_{i}(k)-\right. \\
& \left.x_{i}(k)\right)+c_{2} \times r_{2} \times\left(\text { gbest }_{i}(k)-x_{i}(k)\right), \\
& x_{i}(k+1)=x_{i}(k)+v_{i}(k+1),
\end{aligned}
$$

where $v_{i}(k+1)$ is the updated velocity in $i$-th particle at iteration $k+1, x_{i}(k+1)$ is the updated position in $i$-th particle at iteration $k+1 . c_{1}$ and $c_{2}$ are two acceleration coefficients called learning factors, namely cognitive learning factor and social learning factor, respectively; their reasonable values are assigned to 2.5 respectively according to the study (Feng et al., 2018); $r_{1}$ and $r_{2}$ are uniformly disturbed random numbers within 0 and $1 ; v_{i}()$ and $x_{i}()$ are the velocity and position of $i$-th particle in search space, respectively. $w(k+1)$ is the inertia weight, which describes the inertia of velocity influencing the $k+1$-th iteration. The $w(k+1)$ can be expressed as:

$$
w(k+1)=w_{\text {ini }}-\left(w_{\text {ini }}-w_{\text {end }}\right) \times \frac{k+1}{\text { max_iteration }},
$$

where $w_{\text {ini }}$ is the initial inertia weight and $w_{\text {end }}$ is the end inertia weight when iterating to the maximum evolution algebra. Their reasonable values are assigned as 1.3 and 0.1 , respectively, according to studies (Feng et al., 2018; Wang et al., 2017). A generic PSO is depicted in Figure 2.

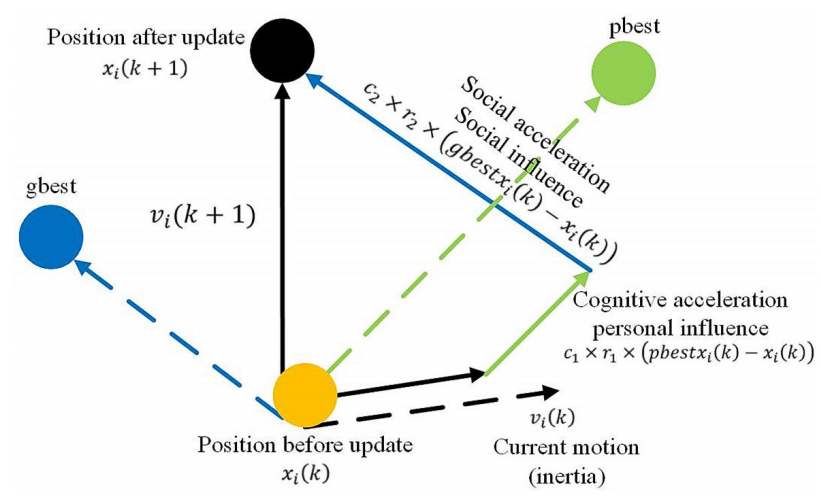

Figure 2. PSO optimization diagram

\subsection{Markov Chain (MC) and Particle swarm optimization (PSO) integration}

After establishing the MC and PSO models, the simulated MC-PSO model is integrated to find the Pareto-optimal solution for pavement maintenance (see Figure 3). The developed MC model first calculates the transition probability based on the surveyed deterioration periods, then forming the TPM, the road pavement mileage after deterioration can be computed based on the TPM and the surveyed pavement initial states, where are then input into the PSO model. In the PSO model, the particles of PSO representing the maintenance activities are initiated from possible maintenance mileage using uniform random 


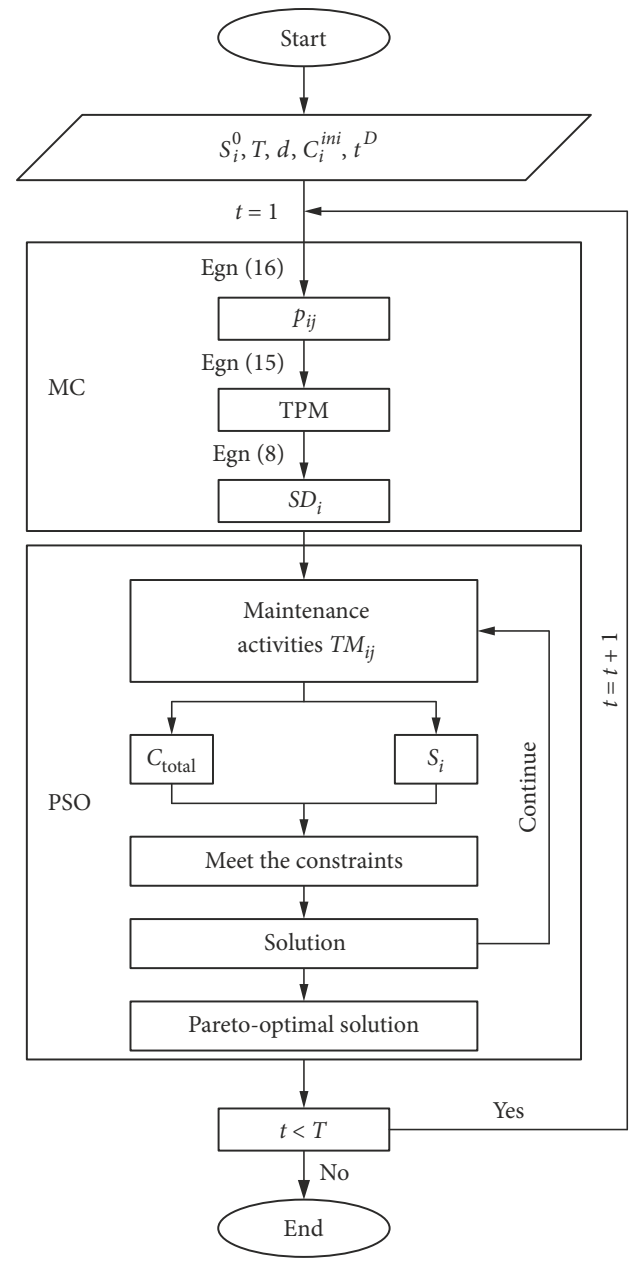

Figure 3. MC-PSO function integration

selection. When the simulation results meet al. the constraints introduced in Section 3, one solution is obtained, which will update the swarm's global and local best information to continue searching the Pareto-optimal solution. In the maintenance horizon, the pavement data is iterated once a year to find the Pareto-optimal solution for pavement maintenance.

The MC-PSO integration executes two different types of loops. The first is where the particles of PSO search the Pareto-optimal solution obtained at the end of the loop procedure under constraints; the second is to find the Pareto-optimal solution in different years. By this integration, the multi-objective optimal solution alongside the pavement conditions can be quickly converged to support pavement management.

\subsection{The formulation for implementation}

The procedure of the developed integrated approach was programmed as a prototype in Python code running on the PyCharm ${ }^{\circledR}$ programming software as shown in Algorithm 1 (Table 1). First, the road pavement section for maintenance is selected, and then to obtain the state distribution of the road pavement section by engineer practitioners based on the experience and knowledge, and to get familiar with maintenance requirements from the road agencies. The initial information related to the road pavement section was programmed in Python code, such as the initial road pavement conditions, unit maintenance costs in different states and maintenance horizon, etc. Correspondingly, the transition probability of the road pavement section together with the parameters of PSO are provided. Then, the MC-PSO algorithm is run to obtain feasible solutions for searching for the Pareto-optimal solution (Table 1).

\section{Numerical case study}

\subsection{General description}

To illustrate the effectiveness of the proposed integrated approach in this research, a case study is applied on a reallife application in the study (Akyildiz, 2008; Jesus et al., 2011) based on Virginia Department of Transportation (VDOT) highway planning district containing 500 lanemiles of I-81 and I-581 four-lane interstate highways in Salem District with a maintenance horizon of 15 years. The I-81 interstate highway reaches Tennessee in the south and New York in the north, its auxiliary highway I-581 connects Virginia. The pavement condition data were collected by VDOT in the early years of the 21 st century (Akyildiz, 2008). The road pavement states are $[0,1,2,3,4]=[$ Excellent, Good, Fair, Poor, Very poor $]$; the initial road pavement mileage in different states is $\left[S_{00}, S_{01}, S_{02}, S_{03}, S_{04}\right]=[75,175,150,75,25]$; the deterioration periods of adjacent pavement states are $\left[t_{01}^{D}, t_{12}^{D}, t_{23}^{D}, t_{34}^{D}\right]=$ $[3,5,3,4]$; the target mileage for different states each year are $\left[S_{0}^{t g}, S_{1}^{t g}, S_{2}^{t g}, S_{3}^{t g}, S_{4}^{t g}\right]=[125,200,100,50,25]$. There are 7 types of maintenance activities (see Figure 4), and the unit maintenance cost of each maintenance activity is different. The unit maintenance costs of different maintenance activities and their combinations are ranked as follows: $C M_{10}, C M_{21}, C M_{20}, C M_{21}+C M_{10}, C M_{31}, C M_{31}+$ $C M_{10}, C M_{30}, C M_{41}, C M_{41}+C M_{10}, C M_{40}$.

\subsection{Results summary}

According to the proposed integrated approach, the transition probabilities in the TPM of the MC are first computed for predicting the future pavement conditions followed by simulating the maintenance activities to obtain the Pareto-optimal solution for determining maintenance strategies. The MC-PSO model written in Python 3.5 code running on the $\mathrm{PyCharm}^{\circledR}$ programming software was performed on a workstation with an Intel(R) Core(TM) i7-7700HQ CPU @2.80Hz, 2.81GHz, and 16.0G RAM, on the Windows 10 Home operating system.

The appropriate parameter selection of PSO is the guarantee to obtain the optimal solution efficiently and effectively considering the computing loads. Based on the determination of learning factors and inertia weights, the simulation iteration of PSO is an important parameter for 
optimization. The simulation results obtained with different iterations are shown in Figure 5. When there are more than 1500 iterations, the simulation accuracy of case 1 and case 2 tends to be stable, both reaching $100 \%$. The simulation time required for 2000 iterations of case 1 and case 2 is $743 \mathrm{~s}$ and $645 \mathrm{~s}$, respectively, and each additional 1000 iterations of case 1 and case 2 requires an average increase of about $262 \mathrm{~s}$ and 315s, respectively. Therefore, fully considering the simulation accuracy, simulation time, and simulation results stability, 2000 iterations can be selected as a reasonable number.

Table 1. Algorithm

Algorithm 1. Pseudocode for automatic calculation procedure of the integrated method.

Preparation:

1 Determine the road pavement section for maintenance;

2 Identify the state distribution of the road pavement section;

3 Obtain the maintenance requirements from the road agencies;

Initialization:

4 Identify pavement maintenance requirements parameters, check and adjust parameters if necessary, i.e. $S_{i}^{0}, C_{i j}^{\text {ini }}, C_{\text {total }}^{t}, T$ and $d$; 5 Set the TPM of the MC;

6 Initialize the PSO parameters, i.e., $w_{\text {ini }}$, $w_{\text {end }}$, dimension, number of particles, max_iteration;

7 Set the range of constraints for each particle's phase initialize position and the initialize velocity;

MC-PSO:

8 For $t$ in $T$ do

9 Calculate new road mileage after deterioration in state $i$;

10 For each particle $i$ do

11 For each dimension $d$ do

12 Initialize position and initialize velocity;

13 End

14 End

15 Iteration $k=1$ do

16 For each particle $i$ do

17 For each dimension $d \mathbf{d o}$

18 Calculate weight according to the equation $w(k)=w_{\text {ini }}-\left(w_{\text {ini }}-w_{\text {end }}\right) \times \frac{k}{\max \text { iteration }}$;

19 Calculate velocity according to the equation

$v_{i}(k+1)=w(k) \times v_{i}(k)+c_{1} \times r_{1} \times\left(\right.$ pbestx $\left._{i}(k)-x_{i}(k)\right)+c_{2} \times r_{2} \times\left(\right.$ gbestx $\left._{i}(k)-x_{i}(k)\right)$;

Calculate position according to the equation $x_{i}(k+1)=x_{i}(k)+v_{i}(k+1)$;

End

Calculate the fitness value; calculate the maintenance cost;

Check the maintenance cost;

Evaluate fitness value, maintenance cost and maintenance mileage;

update swarm gbest and particle pbest positions;

End

update gbest and particle pbest

$k=k+1$;

29 End

30 Save gbest.

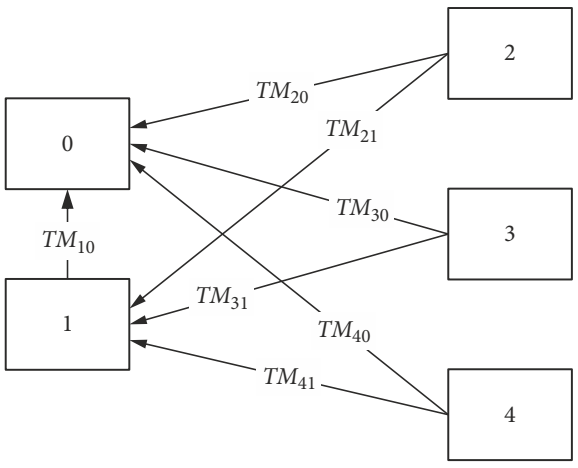

Figure 4. Illustration of the maintenance activities

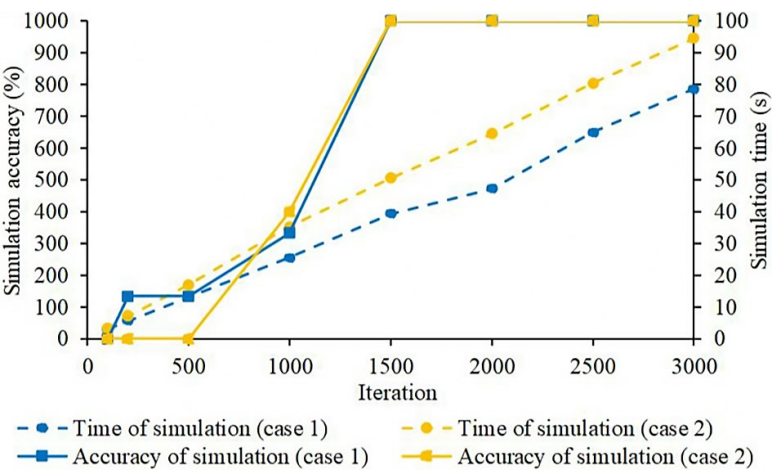

Figure 5. Simulation iteration selection for PSO-based optimization 


\subsubsection{Calculation of the probability transition matrix}

To predict the future pavement conditions, the TPM of the MC is used. The set of the transition probabilities generated by Eqn (16) are represented as a transition probability matrix according to the Eqn (15) and is shown below in Eqn (20).

$$
\begin{array}{r}
\text { State } 0 \\
0 \\
0 P M= \\
1 \\
2 \\
3 \\
4
\end{array}\left(\begin{array}{c|c|c|c|c}
0.67 & 0.26 & 0.05 & 0.02 & 2 \\
\hline 0 & 0.80 & 0.13 & 0.05 & 0.02 \\
\hline 0 & 0 & 0.67 & 0.25 & 0.08 \\
\hline 0 & 0 & 0 & 0.75 & 0.25 \\
\hline 0 & 0 & 0 & 0 & 1
\end{array}\right) .
$$

These values in the matrix represent the annual deterioration rate of the road pavement under the impact of uncertain environmental factors and traffic loads, meanwhile, it also describes the trend distribution of road pavement states.

\subsubsection{Case 1: maximizing pavement performance with the budget limit}

From the perspective of the user, the consideration of maximizing pavement performance with the budget limit is taken for granted. PSO model is consequently programmed by considering Eqn (2) and constraints. After the calculation of the MC, the PSO model is used to simulate the feasible solutions for searching the Pareto-optimal solution. For maximizing the pavement performance with the budget limit (i.e., minimizing the road pavement mileage in the states Fair, Poor, and Very poor), any budget will be prioritized to maximize the road pavement performance with priority given to maintaining state Excellent, followed by state Good.

The simulation process of the PSO is conducted for searching the Pareto-optimal solution. The values are tracked during the simulation process. One example of the 11th year is shown in Figure 6. As can be seen, in the process of searching the global optimal particle position,

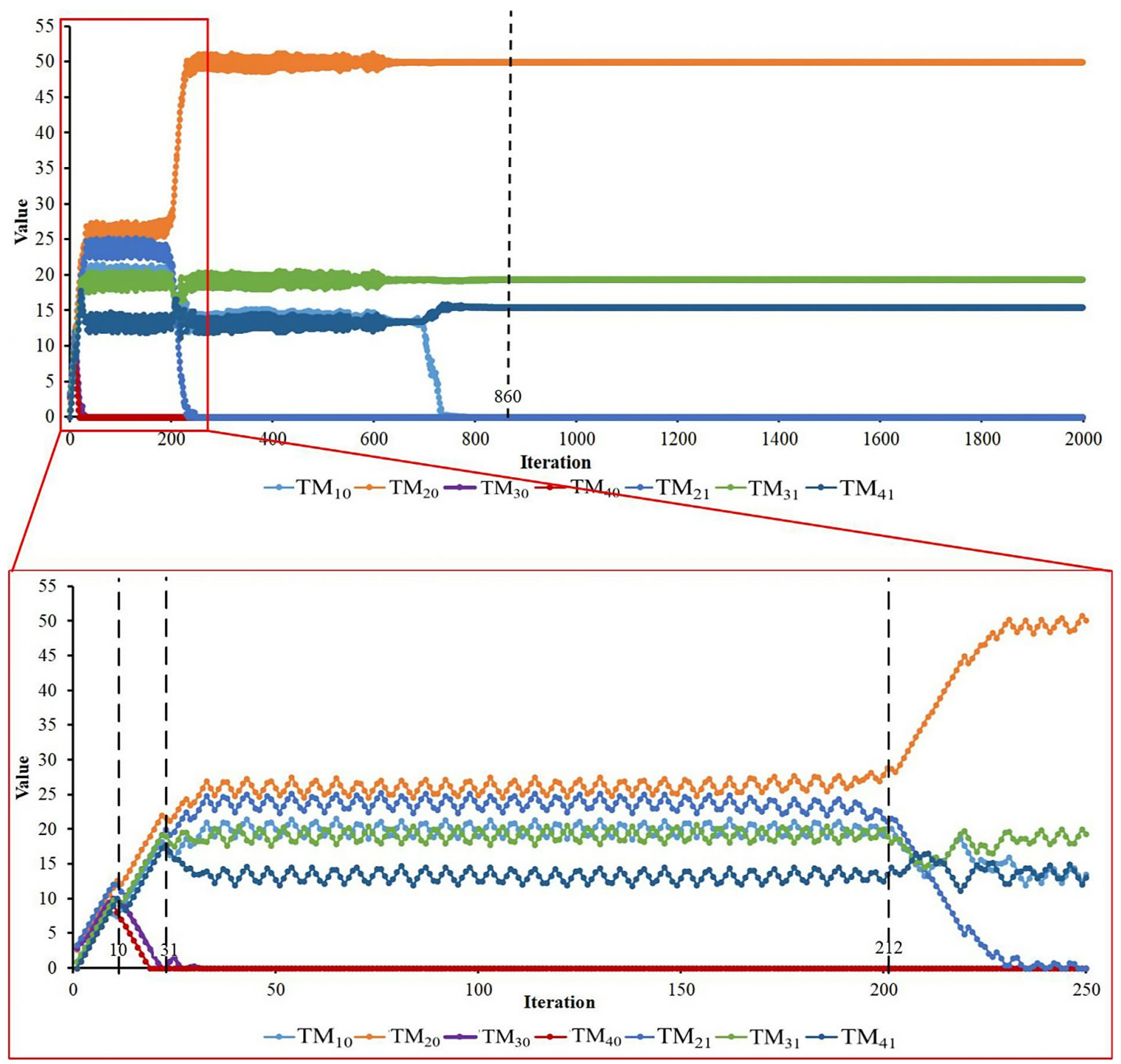

Figure 6. Simulation process of searching Pareto-optimal solution with budget limit 
the values initially fluctuate significantly and then gradually stabilize. The particle swarm had several obvious optimization changes, which reflects the particle swarm jumps out of the local optimum trap at these iterations, such as the 10th, 31th, and 212th iterations. After the 860th iteration, the values on the particle swarm for achieving the objective tend to be stable, indicating that the Paretooptimal solution is found, with values of $0,49.96,0,0,0$, $19,33,15.50$, respectively.

Figure 7 shows the maintenance horizon-based $\mathrm{Pa}$ reto maintenance strategies. To maximize the pavement performance with the budget limit, there are three types of maintenance activities: the maintenance activity from Fair state pavement into Excellent state pavement $\left(T M_{20}\right)$; the maintenance activity from Poor state pavement into Good state pavement $\left(T M_{31}\right)$ and the maintenance activity from Very poor state pavement into Good state pavement $\left(T M_{41}\right)$. As can be seen in Figure 7 , the total budget in the first year is devoted to maintain the pavement in the state Fair and make it to state Excellent, with a maintenance mileage of 88.49 miles. With the reduction of the mileage of the Fair state pavement, the remaining budget is spent on maintaining Poor and Very poor state pavement in the second and third years, respectively, to make them into Good state pavement. It is worth noting that Figure 8 shows the mileage held in each state each year, which can further reveal the maintenance activities performed during the maintenance horizon. Obviously, the maintained mileage of the Fair state pavement after the second year is the mileage of the pavement in state Fair after the deterioration in that year. Likewise, the maintenance activity for Poor state condition is to maintain all the deteriorated mileage in state Poor after the third year. In addition to supporting maintenance activities $T M_{20}$ and $T M_{31}$ in the third year, the budget supports maintenance activity $T M_{41}$, which accounts for a budget ratio of 0.28:0.61:0.11 (see Figure 9), respectively. The zero inventory of Fair and Poor state pavement directly leads to a peak of maintenance mileage in maintenance activity $T M_{41}$ in the fourth year due to higher budget being allocated for maintenance activity $T M_{41}$. From Figure 8, there is a peak of pavement inventory in state Excellent in the second year, the explanation for which is due to the fact that the pavement mileage transferred from state Fair to state Excellent (53.47 miles) is greater than that of deterioration in state Excellent (45.78 miles), which is similar to the peak of pavement inventory in state Very poor in the third year. After the fourth year, the mileage of Excellent and Good state pavement every year is increased by the maintenance activities driven by budget, which leads to the annual maintenance mileage of deteriorated Fair and Poor state pavement also increasing year by year. These indirectly affect the maintenance mileage of the Very poor state pavement decreasing year by year owing to the reduction of the remaining maintenance budget for maintaining the Very poor state pavement.

The mileage of Excellent and Good state pavement increases gradually, while the mileage of the Fair, Poor, and Very poor state pavement decreases, which is beneficial

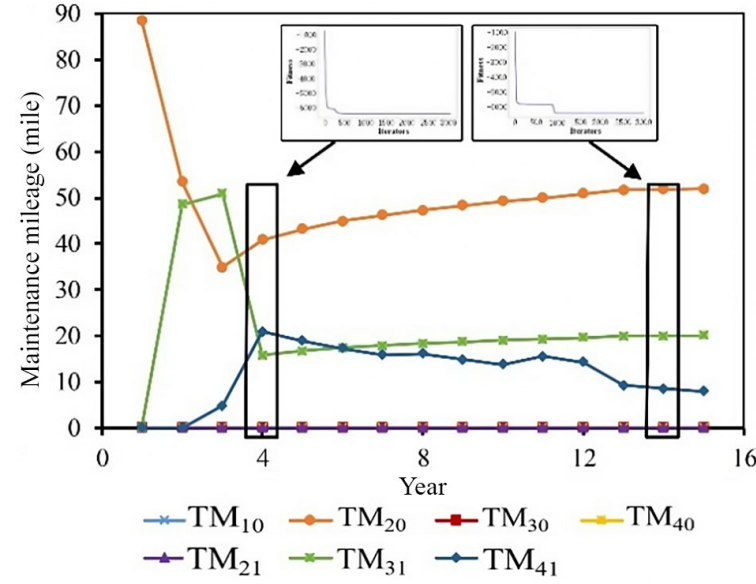

Figure 7. Maintenance mileage of different maintenance activities with maintenance horizon

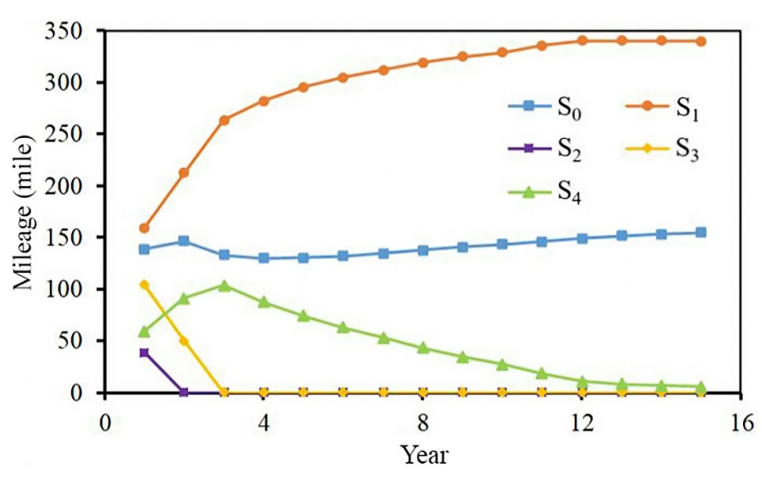

Figure 8. Mileage in different pavement states with maintenance horizon

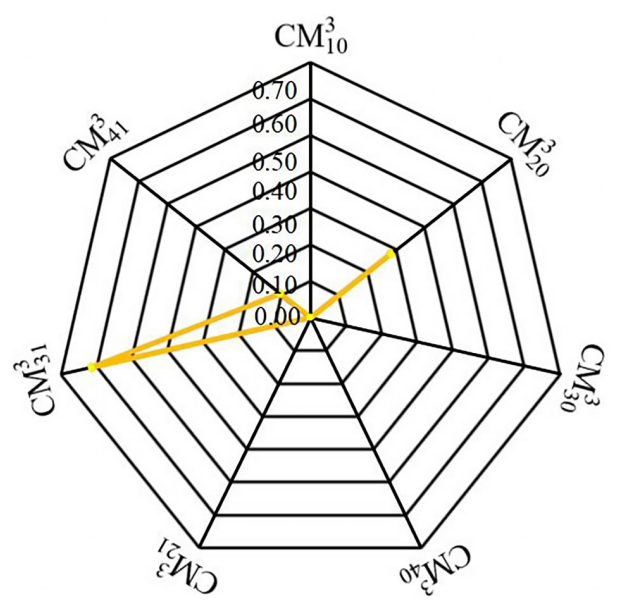

Figure 9. Proportion distribution of maintenance cost in the third year

for users to have better experience and comfort. More importantly, the reduction of bad road pavement can reduce the occurrence of traffic accidents.

In summary, the PSO performs well in terms of maximizing pavement performance while simultaneously considering the budget limit, which achieves good simulation results in searching the Pareto-optimal solution with the maintenance horizon after predicting the future pavement conditions by MC. 


\subsubsection{Case 2: minimizing the maintenance} costs with maintenance targets

From the perspective of the contractor, consideration of reaching the maintenance targets at the lowest cost is taken for granted under the supervision of managers. To minimize the maintenance costs with maintenance targets, the PSO model is programmed by considering Eqn (3), target mileage, and excluding constraints (10). Figure 10 as one example of the 8th year shows the tracked and recorded simulation process of the PSO for searching for the Pareto-optimal solution. In the initial simulation phase, the values obviously fluctuated more seriously, and then $T M_{21}, T M_{40}$, and $T M_{20}$ gradually evolve to 0 . After the 878 th iteration, the values on the objectives tend to be stable, indicating that Pareto-optimal solution is found with values of $41.25,0,0,0,0,24.68,24.40$, respectively.

Figures 11 and 12 show the maintenance mileage and maintenance cost respectively. Considering the maintenance targets, the road pavement undergoes relatively large maintenance in the first year. Maintenance activities take place in $T M_{10}, T M_{20}, T M_{31}$ and $T M_{41}$, with maintenance mileage of 47.25 miles, 27 miles, 54 miles, and 34.25 miles, respectively (see Figure 11). Correspondingly, the maintenance costs of different maintenance activities in the first year is very high, reaching $\$ 1,392,199, \$ 1,830,735$, $0,0,0, \$ 5,497,632$, and $\$ 6,443,623.75$, respectively (see Figure 12). After the first year, the road pavement mileage stayed in different states has reached the maintenance targets, except for states Good and Fair. The reason for state Fair is that the decreased mileage is greater than the increased mileage from the second year to the ninth year, which makes the mileages decrease, while the mileage in the state Good increases slightly due to consideration of the maintenance cost minimization. From Figure 12, it is evident that maintenance cost increases slightly every year after the first year. The explanations for the condition are that not only does the increase in the mileage for maintenance to Good state pavement lead to an increase in the maintenance cost, but the unit maintenance cost increases year by year.

In general, despite the constraints of maintenance targets with the maintenance horizon, the results show that the PSO performs well and all the Pareto-optimal solutions are successfully found. It can be concluded that the approach is practical in real situations for determining pavement maintenance strategies.

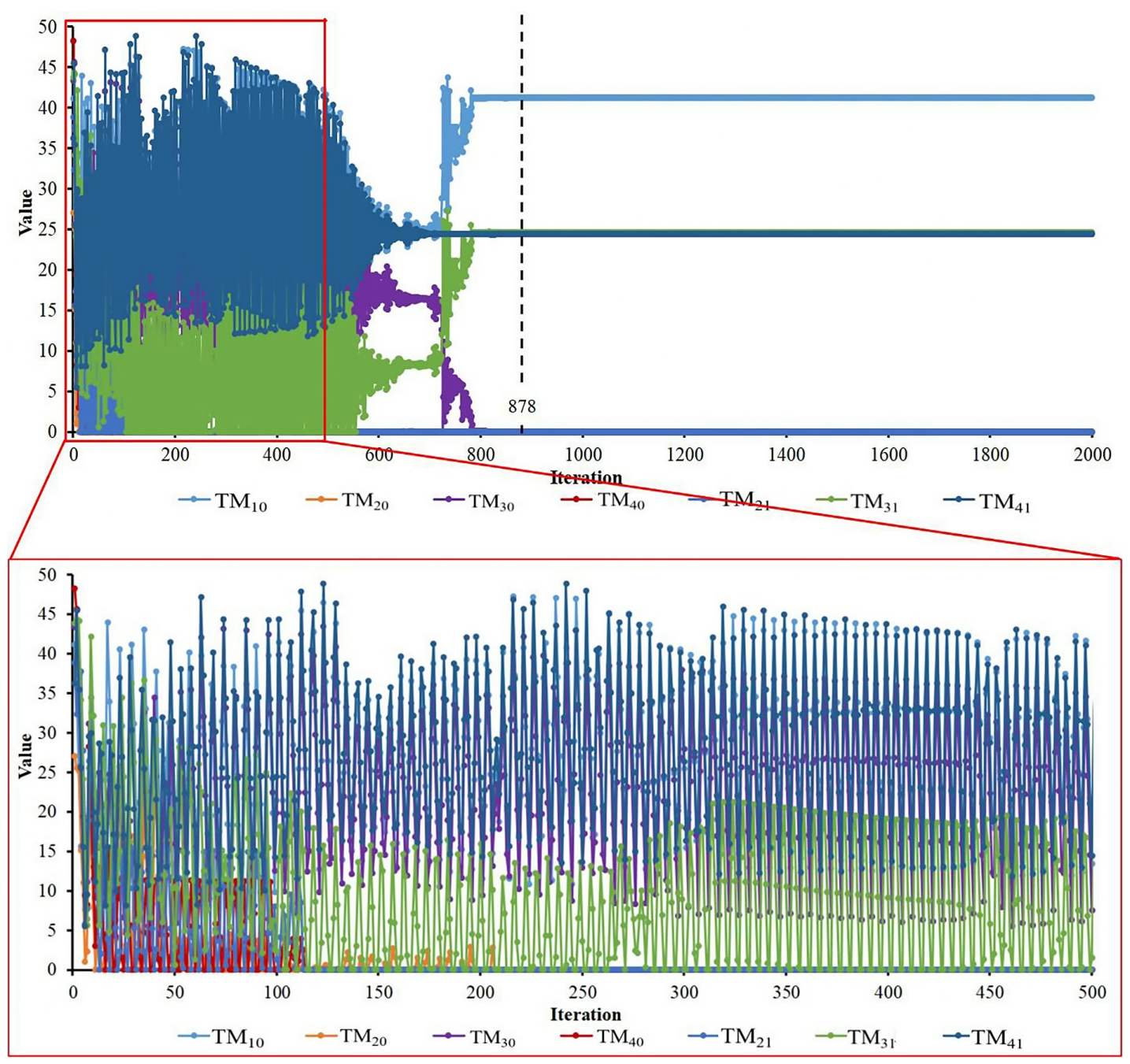

Figure 10. Simulation process of searching Pareto-optimal solution with maintenance targets 


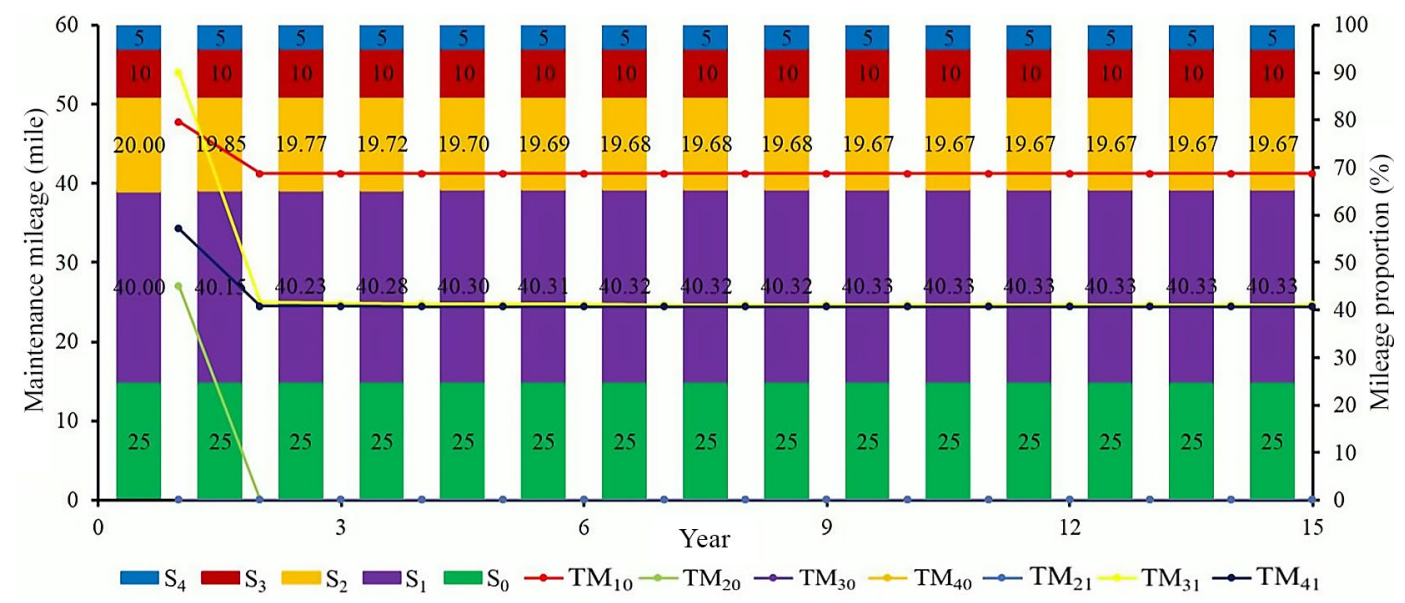

Figure 11. Mileage distribution with maintenance horizon

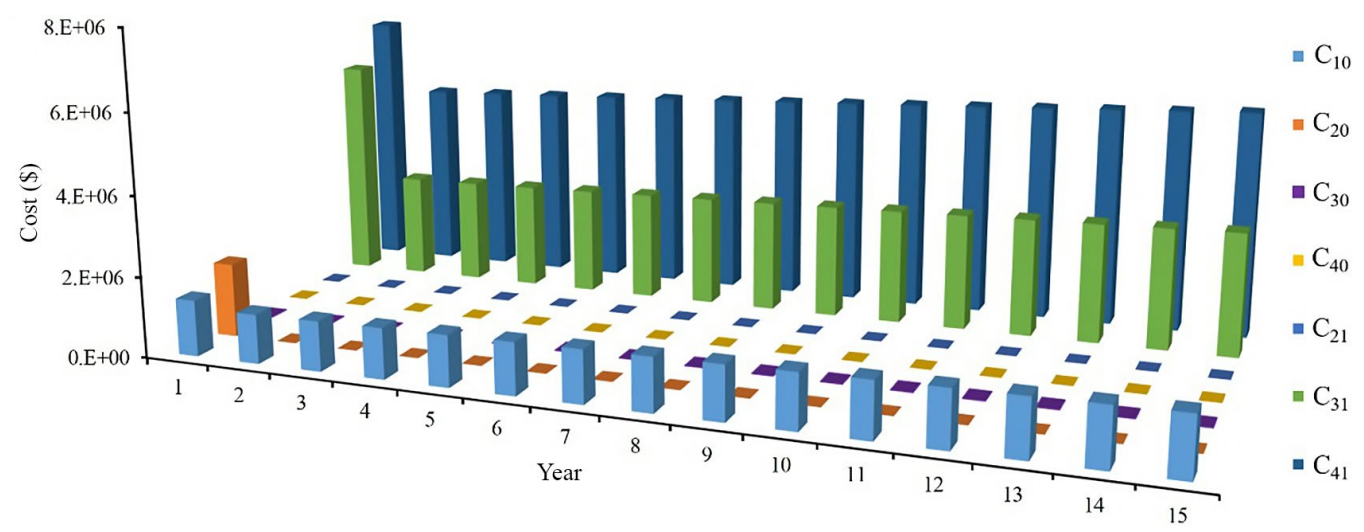

Figure 12. Cost of different maintenance activities with maintenance horizon ( $C$ represents the total annual maintenance cost)

\section{Discussions}

The proposed approach integrates the Markov chain for predicting the future pavement conditions and particle swarm optimization algorithm for searching the Paretooptimal solution to determine maintenance strategies. This allows the straightforward improvement of the pavement performance through maintenance based on the Paretooptimal solution for promoting pavement sustainability. In the case proposed in this research, the PSO model is applied to the pavement maintenance field based on pavement condition predicted by the Markov chain, and then the optimal pavement maintenance strategies from two maintenance perspectives for 15 years are provided. To examine the results obtained by the proposed integrated approach, a comparative study is carried out using the traditional technique linear program. From the results of the two methods, all the results are the same for these two cases, which demonstrates that the proposed integrated approach is effective, reliable, and credible for determining pavement maintenance strategies.

Figures 13 and 14 show the total present maintenance costs and mileage of two cases, respectively. It is evident that the total present maintenance cost in case 1 is significantly less than that of the case 2 over the maintenance horizon. The present maintenance cost of case 2 exceeds the present maintenance cost of case 1 by $11.99 \%$. How- ever, under the incentive of high cost, the total mileage of the Good and Excellent state pavement from the case 2 is lower than that from the case 1 except for the first year as shown in Figure 14. One reason for the condition is that part of the cost goes toward maintaining the Good state pavement to the Excellent state pavement for reaching maintenance targets as shown in Figure 12. Although the total present maintenance cost of the case 1 is slightly lower while the pavement mileage in states Good or Excellent is more, it is noteworthy that the mileage of the first nine years in state Very poor is always quite large as shown in Figure 8, which may present potential risks.

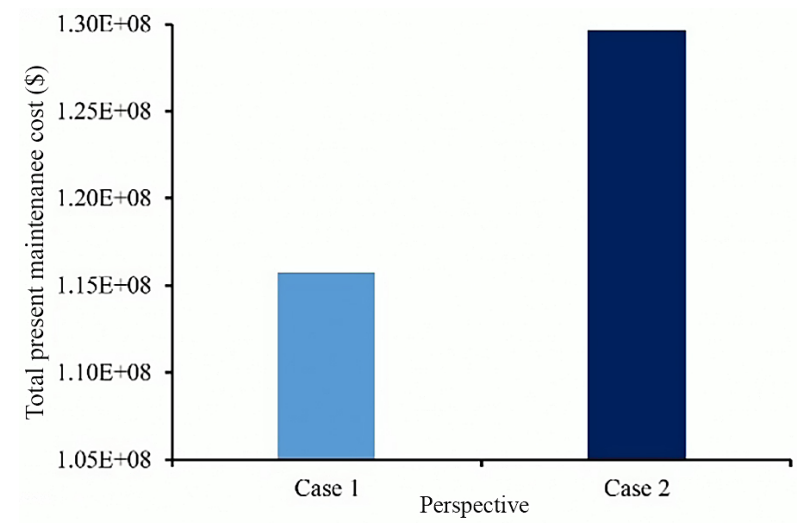

Figure 13. Total present maintenance costs of two cases 


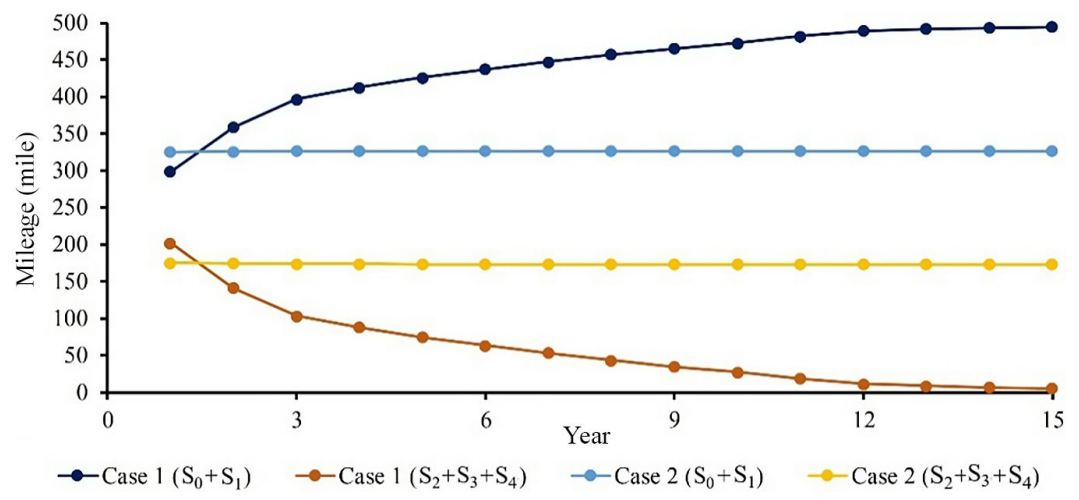

Figure 14. Mileage of two cases with maintenance horizon

Regarding the road users, contractors, and road agency, the proposed integrated approach is beneficial regardless of the dynamic and uncertain problem under considered. The advantage of the integrated approach is demonstrated by the fact that using the integrated approach, the capability to automatically determine the optimal maintenance strategy is performed at the given constrains, while addressing the problem, and the future pavement conditions can be predicted according to its past performance in the field operation scenario. This is a better trade-off between maintenance targets and maintenance budget can be achieved, which, in turn, results in remarkable gains of assisting pavement stakeholders to improve productivity for effective long-term pavement maintenance. On the other hand, there are still some shortcomings in the integrated approach, and some improvements need to be carried out in the future to address the following challenges: (a) the surveys of the initial road pavement mileage in different states rely on the rich experience and knowledge of engineering practitioners, to perform the task is laborintensive, time-consuming, inefficient and non-objective. Therefore, an automated survey of the road pavement mileage in different states needs to be developed; (b) fixed transition probability and discount rate cannot fully reflect the real-life situation, an adjustable scheme needs to be developed that integrates periodic road pavement survey to prevent the prediction errors of the road pavement condition to achieve a more effective and reliable pavement maintenance strategy. Furthermore, other objective maintenance strategies can be developed in addition to those proposed in this research by the integrated approach, such as the maintenance strategy with the minimum maintenance cost to maximize pavement performance.

\section{Conclusions}

This research proposes an integrated approach based on Markov chain and particle swarm optimization algorithm to predict future pavement conditions that consider the uncertainty followed by optimizing the pavement maintenance strategies for maintenance to promote pavement sustainability according to the requirements and limitations of road agencies. The integrated approach can in- clude the transfer probability of the pavement state, which is represented as the pavement deterioration impacted by uncertain environmental factors and traffic loads during road operation. Moreover, it enables pavement performance or maintenance cost as the optimized objective by employing the PSO to search for the Pareto-optimal solution for a road pavement section based on a set of generated potentially optimal pavement maintenance solutions, all while satisfying multiple constraints through identifying decision variables.

To verify the performance of the proposed integrated approach, a case study based on 500 lane-miles of interstate highways with a maintenance horizon of 15 years is carried out. From the results, the dynamic long-term changes in pavement mileage, allocated cost, and maintenance mileage are revealed for decision-making by two cases. A comparison with the linear program demonstrates that the integrated approach is reliable, credible, and practical in real situations for determining pavement maintenance strategy.

In summary, the proposed integrated approach presents an effective and reliable solution to determine the pavement maintenance strategy that can be employed to promote pavement sustainability. Nevertheless, some limitations need to be addressed. In future research, attention should be paid to the correction of the transition probability through periodic road inspection to reduce the road pavement prediction error. Additionally, more cases need to be tested to extend the application of the proposed integrated approach.

\section{Acknowledgements}

We would like to thank the editors and reviewers for their constructive and insightful comments.

\section{Funding}

This research was supported by the National Social Science Fund of China (No. 18ZDA043). The work described in this paper was also funded by the National Natural Science Foundation of China (NSFC) (No. 71841024, No. 71671053, No. 71771067), the National Key Re- 
search and Development Program of China (No. 2016YFC0701800 and No. 2016YFC0701808), and the Department of Science and Technology of Guangdong Province (No. 2019B101001019).

\section{Author contributions}

All authors were involved in conceiving the study, data analysis and structure of the paper. Ankang Ji conducted scientific research, performed data analysis, and wrote the paper. Xiaolong Xue and Yuna Wang reviewed and edited the manuscript drafts. Xiaowei Luo and Minggong Zhang polished the language and checked the grammatical errors.

\section{Disclosure statement}

The authors declare that they have no known competing financial interests or personal relationships that could have appeared to influence the work reported in the manuscript.

\section{References}

Ahmed, K., Al-Khateeb, B., \& Mahmood, M. (2019a). Application of chaos discrete particle swarm optimization algorithm on pavement maintenance scheduling problem. Cluster Computing, 22(2), 4647-4657.

https://doi.org/10.1007/s10586-018-2239-3

Ahmed, K., Al-Khateeb, B., \& Mahmood, M. (2019b). A multiobjective particle swarm optimization for pavement maintenance with chaos and discrete. Journal of Southwest Jiaotong University, 54(3).

https://doi.org/10.35741/issn.0258-2724.54.3.5

Akyildiz, S. (2008). Development of new network-level optimization model for Salem district pavement maintenance programming. Virginia Tech. http://hdl.handle.net/10919/34827

Alothaimeen, I., \& Arditi, D. (2019). Overview of multi-objective optimization approaches in construction project management. In Multi-criteria optimization - Pareto-optimal and related principles. IntechOpen.

https://doi.org/10.5772/intechopen.88185

Barone, G., \& Frangopol, D. M. (2014). Life-cycle maintenance of deteriorating structures by multi-objective optimization involving reliability, risk, availability, hazard and cost. Structural Safety, 48, 40-50.

https://doi.org/10.1016/j.strusafe.2014.02.002

Biondini, F., \& Frangopol, D. M. (2016). Life-cycle performance of deteriorating structural systems under uncertainty. Journal of Structural Engineering, 142(9), F4016001.

https://doi.org/10.1061/(ASCE)ST.1943-541X.0001544

Bosurgi, G., \& Trifirò, F. (2005). A model based on artificial neural networks and genetic algorithms for pavement maintenance management. International Journal of Pavement Engineering, 6(3), 201-209. https://doi.org/10.1080/10298430500195432

Chang, J. R. (2013). Particle swarm optimization method for optimal prioritization of pavement sections for maintenance and rehabilitation activities. Applied Mechanics and Materials, 343, 43-49.

https://doi.org/10.4028/www.scientific.net/AMM.343.43

Chootinan, P., Chen, A., Horrocks, M. R., \& Bolling, D. (2006). A multi-year pavement maintenance program using a stochastic simulation-based genetic algorithm approach. Transportation Research Part A - Policy and Practice, 40(9), 725-743. https://doi.org/10.1016/j.tra.2005.12.003

Chou, J.-S., \& Le, T.-S. (2011). Reliability-based performance simulation for optimized pavement maintenance. Reliability Engineering \& System Safety, 96(10), 1402-1410. https://doi.org/10.1016/j.ress.2011.05.005

Chou, J.-S., \& Le, T.-S. (2014). Probabilistic multiobjective optimization of sustainable engineering design. KSCE Journal of Civil Engineering, 18(4), 853-864.

https://doi.org/10.1007/s12205-014-0373-x

Eberhart, R., \& Kennedy, J. (1995). A new optimizer using particle swarm theory. In Proceedings of the Sixth International Symposium on Micro Machine and Human Science (IEEE), Nagoya, Japan. https://doi.org/10.1109/MHS.1995.494215

Elhadidy, A. A., Elbeltagi, E. E., \& Ammar, M. A. (2015). Optimum analysis of pavement maintenance using multi-objective genetic algorithms. HBRC Journal, 11(1), 107-113. https://doi.org/10.1016/j.hbrcj.2014.02.008

Feng, K., Lu, W., Chen, S., \& Wang, Y. (2018). An integrated environment-cost-time optimisation method for construction contractors considering global warming. Sustainability, 10(11), 4207. https://doi.org/10.3390/su10114207

Figueredo, G. P., Owa, K., \& John, R. (2020). Multi-objective optimization for time-based preventive maintenance within the transport network: a review. Academic and Library Computing.

Gao, H., \& Zhang, X. (2013). A Markov-based road maintenance optimization model considering user costs. Computer-Aided Civil and Infrastructure Engineering, 28(6), 451-464.

https://doi.org/10.1111/mice.12009

Gopalakrishnan, K. (2010). Neural network-swarm intelligence hybrid nonlinear optimization algorithm for pavement moduli back-calculation. Journal of Transportation Engineering, 136(6), 528-536.

https://doi.org/10.1061/(ASCE)TE.1943-5436.0000128

Gopalakrishnan, K. (2013). Particle swarm optimization in civil infrastructure systems: state-of-the-art review. Chapter 3 in A. H. Gandomi, X.-S. Yang, S. Talatahari, \& A. H. Alavi (Eds.), Metaheuristic applications in structures and infrastructures (pp. 49-76). Elsevier Inc.

https://doi.org/10.1016/B978-0-12-398364-0.00003-6

Jesus, M., Akyildiz, S., Bish, D. R., \& Krueger, D. A. (2011). Network-level optimization of pavement maintenance renewal strategies. Advanced Engineering Informatics, 25(4), 699-712. https://doi.org/10.1016/j.aei.2011.08.002

Khavandi Khiavi, A., \& Mohammadi, H. (2018). Multiobjective optimization in pavement management system using NSGA-II method. Journal of Transportation Engineering, Part B: Pavements, 144(2), 04018016.

https://doi.org/10.1061/JPEODX.0000041

Kim, S., Ge, B., \& Frangopol, D. M. (2019). Effective optimum maintenance planning with updating based on inspection information for fatigue-sensitive structures. Probabilistic Engineering Mechanics, 58, 103003. https://doi.org/10.1016/j.probengmech.2019.103003

Konak, A., Coit, D. W., \& Smith, A. E. (2006). Multi-objective optimization using genetic algorithms: A tutorial. Reliability Engineering \& System Safety, 91(9), 992-1007. https://doi.org/10.1016/j.ress.2005.11.018

Lamptey, G., Labi, S., \& Li, Z. (2008). Decision support for optimal scheduling of highway pavement preventive maintenance 
within resurfacing cycle. Decision Support Systems, 46(1), 376-387. https://doi.org/10.1016/j.dss.2008.07.004

Lea, J. D., \& Harvey, J. T. (2015). Using spatial statistics to characterise pavement properties. International Journal of Pavement Engineering, 16(3), 239-255.

https://doi.org/10.1080/10298436.2014.942856

Lethanh, N., \& Adey, B. T. (2013). Use of exponential hidden Markov models for modelling pavement deterioration. International Journal of Pavement Engineering, 14(7), 645-654. https://doi.org/10.1080/10298436.2012.715647

Lethanh, N., Kaito, K., \& Kobayashi, K. (2015). Infrastructure deterioration prediction with a poisson hidden Markov model on time series data. Journal of Infrastructure Systems, 21(3), 04014051.

https://doi.org/10.1061/(ASCE)IS.1943-555X.0000242

Mandiartha, P., Duffield, C. F., Thompson, R. G., \& Wigan, M. R. (2017). Measuring pavement maintenance effectiveness using Markov chains analysis. Structure and Infrastructure Engineering, 13(7), 844-854.

https://doi.org/10.1080/15732479.2016.1212901

Moazami, D., Behbahani, H., \& Muniandy, R. (2011). Pavement rehabilitation and maintenance prioritization of urban roads using fuzzy logic. Expert Systems with Applications, 38(10), 12869-12879. https://doi.org/10.1016/j.eswa.2011.04.079

Morcous, G., \& Lounis, Z. (2005). Maintenance optimization of infrastructure networks using genetic algorithms. Automation in Construction, 14(1), 129-142.

https://doi.org/10.1016/j.autcon.2004.08.014

Moreira, A. V., Tinoco, J., Oliveira, J. R., \& Santos, A. (2018). An application of Markov chains to predict the evolution of performance indicators based on pavement historical data. International Journal of Pavement Engineering, 19(10), 937-948. https://doi.org/10.1080/10298436.2016.1224412

Noortwijk, J. M., \& Frangopol, D. M. (2004). Two probabilistic life-cycle maintenance models for deteriorating civil infrastructures. Probabilistic Engineering Mechanics, 19(4), 345359. https://doi.org/10.1016/j.probengmech.2004.03.002

Neal, B., \& Pro, P. (2020). The dererioration of asphalt pavement and its causes. PavementPro.com. https://www.pavemanpro. com/article/deterioration_asphalt_causes/

Osorio-Lird, A., Chamorro, A., Videla, C., Tighe, S., \& TorresMachi, C. (2018). Application of Markov chains and Monte Carlo simulations for developing pavement performance models for urban network management. Structure and Infrastructure Engineering, 14(9), 1169-1181.

https://doi.org/10.1080/15732479.2017.1402064

Pérez-Acebo, H., Bejan, S., \& Gonzalo-Orden, H. (2018). Transition probability matrices for flexible pavement deterioration models with half-year cycle time. International Journal of Civil Engineering, 16(9), 1045-1056.

https://doi.org/10.1007/s40999-017-0254-Z

Panda, T. R., \& Swamy, A. K. (2018). An improved artificial bee colony algorithm for pavement resurfacing problem. International Journal of Pavement Research and Technology, 11(5), 509-516. https://doi.org/10.1016/j.ijprt.2018.04.001

Pandey, M., Yuan, X.-X., \& Van Noortwijk, J. (2009). The influence of temporal uncertainty of deterioration on life-cycle management of structures. Structure and Infrastructure Engineering, 5(2), 145-156. https://doi.org/10.1080/15732470601012154

Pantuso, A., Flintsch, G. W., Katicha, S. W., \& Loprencipe, G. (2019). Development of network-level pavement deterioration curves using the linear empirical Bayes approach. International Journal of Pavement Engineering, 20, 1646912. https://doi.org/10.1080/10298436.2019.1646912
Ramachandran, S., Rajendran, C., \& Amirthalingam, V. (2019). Decision support system for the maintenance management of road network considering multi-criteria. International Journal of Pavement Research and Technology, 12(3), 325-335. https://doi.org/10.1007/s42947-019-0039-7

Roads \& Bridges. (2020). The industry resource for the road and bridge construction market. https://www.roadsbridges.com/

Saha, P., Ksaibati, K., \& Atadero, R. (2017). Developing pavement distress deterioration models for pavement management system using Markovian probabilistic process. Advances in Civil Engineering, Article ID 8292056.

https://doi.org/10.1155/2017/8292056

Santos, J., Ferreira, A., \& Flintsch, G. (2017). A multi-objective optimization-based pavement management decision-support system for enhancing pavement sustainability. Journal of Cleaner Production, 164, 1380-1393.

https://doi.org/10.1016/j.jclepro.2017.07.027

Santos, J., Ferreira, A., Flintsch, G., \& Cerezo, V. (2018). A multi-objective optimisation approach for sustainable pavement management. Structure and Infrastructure Engineering, 14(7), 854-868. https://doi.org/10.1080/15732479.2018.1436571

Santos, J., Ferreira, A., \& Flintsch, G. (2019). An adaptive hybrid genetic algorithm for pavement management. International Journal of Pavement Engineering, 20(3), 266-286.

https://doi.org/10.1080/10298436.2017.1293260

Singh, A. P., Sharma, A., Mishra, R., Wagle, M., \& Sarkar, A. K. (2018). Pavement condition assessment using soft computing techniques. International Journal of Pavement Research and Technology, 11(6), 564-581.

https://doi.org/10.1016/j.ijprt.2017.12.006

Surendrakumar, K., Prashant, N., \& Mayuresh, P. (2013). Application of Markovian probabilistic process to develop a decision support system for pavement maintenance management. International Journal of Scientific \& Technology Research, 2(8), 295-303.

Suresh, K., \& Kumarappan, N. (2013). Hybrid improved binary particle swarm optimization approach for generation maintenance scheduling problem. Swarm and Evolutionary Computation, 9, 69-89. https://doi.org/10.1016/j.swevo.2012.11.003

Tabatabaee, N., \& Ziyadi, M. (2013). Bayesian approach to updating Markov-based models for predicting pavement performance. Transportation Research Record: Journal of Transportation Research Board, 2366, 34-42.

https://doi.org/10.3141/2366-04

Tayebi, N. R., Nejad, F. M., \& Mola, M. (2014). Comparison between GA and PSO in analyzing pavement management activities. Journal of Transportation Engineering, 140(1), 99-104. https://doi.org/10.1061/(ASCE)TE.1943-5436.0000590

Tee, K. F., Ekpiwhre, E., \& Yi, Z. (2018). Degradation modelling and life expectancy using Markov chain model for carriageway. International Journal of Quality \& Reliability Management, 25(6), 1268-1288.

https://doi.org/10.1108/IJQRM-06-2017-0116

Torres-Machi, C., Pellicer, E., Yepes, V., \& Chamorro, A. (2017). Towards a sustainable optimization of pavement maintenance programs under budgetary restrictions. Journal of Cleaner Production, 148, 90-102.

https://doi.org/10.1016/j.jclepro.2017.01.100

U.S. Department of Transportation, Federal Highway Administration. (2020). Impact of environmental factors on pavement performance in the absence of heavy loads.

https://www.fhwa.dot.gov/publications/research/infrastructure/pavements/16084/16084.pdf 
Vyas, V., Singh, A. P., \& Srivastava, A. (2019). Entropy-based fuzzy SWOT decision-making for condition assessment of airfield pavements. International Journal of Pavement Engineering, 20, 1-12.

https://doi.org/10.1080/10298436.2019.1671590

Wang, Y., Feng, K., \& Lu, W. (2017). An environmental assessment and optimization method for contractors. Journal of Cleaner Production, 142, 1877-1891.

https://doi.org/10.1016/j.jclepro.2016.11.097

Yang, C., Remenyte-Prescott, R., \& Andrews, J. D. (2015). Pavement maintenance scheduling using genetic algorithms. International Journal of Performability Engineering, 11(2), 973-1318.

Yepes, V., Torres-Machi, C., Chamorro, A., \& Pellicer, E. (2016). Optimal pavement maintenance programs based on a hybrid greedy randomized adaptive search procedure algorithm. Journal of Civil Engineering and Management, 22(4), 540-550. https://doi.org/10.3846/13923730.2015.1120770

Yu, B., Gu, X., Ni, F., \& Guo, R. (2015). Multi-objective optimization for asphalt pavement maintenance plans at project level: Integrating performance, cost and environment. Transportation Research Part D: Transport and Environment, 41, 64-74. https://doi.org/10.1016/j.trd.2015.09.016

Yu, B., Lu, Q., \& Xu, J. (2013). An improved pavement maintenance optimization methodology: Integrating LCA and LCCA. Transportation Research Part A: Policy and Practice, 55, 1-11. https://doi.org/10.1016/j.tra.2013.07.004

Yuan, X., Zhang, B., Wang, P., Liang, J., Yuan, Y., Huang, Y., \& Lei, X. (2017). Multi-objective optimal power flow based on improved strength Pareto evolutionary algorithm. Energy, 122, 70-82. https://doi.org/10.1016/j.energy.2017.01.071 